\title{
ELISA and Copan Based Evaluation and Analysis of Antibiotic Residues in Cattle Milk in Qazvin, Iran
}

\section{A R T I C L E I N F O}

\section{Article Type}

Original Research

\section{Authors}

Zahra Nemati Niko, $M D^{1}$

Gholam Reza Jahed Khaniki, $P h D^{2}$

Mahsa Alikord, $P h D^{2}$

Ebrahim MolaeeAghaee, $P h D^{2 *}$

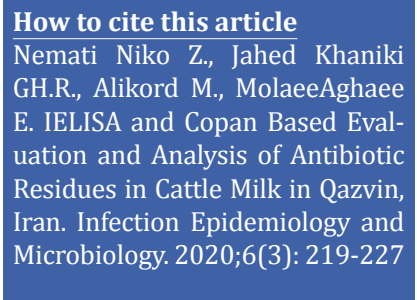

${ }^{1}$ Department of Food Hygiene and Safety, School of Health, Qazvin University of Medical sciences, Qazvin, Iran

${ }^{2}$ Food safety \& Hygiene Division, Environmental Health Engineering Department, School of Public Health, Tehran University of Medical Sciences, Tehran, Iran

\section{* Correspondence}

Address: Tehran University of Medical Sciences, Tehran, Iran. emolaeeaghaee@tums.ac.ir Tel: 0982142933075

\section{Article History}

Received: Jun 25,2020

Accepted: July 30,2020

Published: August 15,2020

\section{A B S T R A C T}

Aims: Daily consumption of milk containing antibiotic residues has become a great public health concern. This study aimed to evaluate the antibiotic residues in cattle raw milk using Copan milk test and specific enzyme-linked immunosorbent (ELISA) kits.

Materials \& Methods: In this study, 92 milk samples were collected from Qazvin province, Iran in two seasons during 2019. All the samples were analyzed by the Copan milk test and competitive ELISA kits to evaluate gentamicin, tetracycline, tylosin, chloramphenicol, penicillin, and sulfonamide residues in milk.

Findings: The results showed that 45 milk samples (48.91\%) were positive for the presence of antibiotic residues. Samples collected in summer were significantly $(p<.05)$ more contaminated with antibiotic residues $(30.43 \%)$ than those collected in winter $(18.47 \%)$. The highest mean contamination was related to sulfonamide $(13.72 \pm 1.21 \mathrm{ng} / \mathrm{mL})$, followed by gentamicin $(13.24 \pm 2.81 \mathrm{ng} / \mathrm{mL})$ and tylosin $(13.15 \pm 1.37 \mathrm{ng} / \mathrm{mL})$ residues, and the lowest mean contamination was related to penicillin residues $(0.007 \pm 0.002 \mathrm{ng} / \mathrm{mL})$. The limit of detection (LOD) was 2, 2.5, 0.02, 8, 0.4, 0.08, and $13 \mathrm{ng} / \mathrm{mL}$ for gentamicin, tylosin, chloramphenicol, sulfamethazine, tetracycline, penicillin, and flumequine, respectively. Chloramphenicol residues were above the maximum residue limit (MRL) according to the Codex and European Commission (EC) $(0 \mathrm{ng} / \mathrm{mL})$ in all the samples. Sulfonamides residues were above the Codex MRL (25 ng/mL) in $33.33 \%$ of the samples.

Conclusion: The results shows that monitoring of antibiotic residues in milk and dairy products is necessary. Indeed, examining the amount of antibiotic residues in dairy products could be an important aspect of their monitoring.

\section{Keywords: Antibiotic, Residues, Milk, Copan, ELISA}

\section{CITATION LINKS}

[1] Gustavsson E, Degelaen J, Bjurling P, Sternesjo A. Determination of beta-lactams in milk using a ... [2] Du B, Wen F, Guo X, Zheng N, Zhang Y, Li S, et al. Evaluation of ... [3] Wang H, Ren L, Yu X, $\mathrm{Hu}$ J, Chen Y, He G, et al. Antibiotic residues in ... [4] Ronquillo MG, Hernandez JC. Antibiotic and synthetic growth ... [5] Tölgyesi Á, Barta E, Sohn M, Sharma VK. Determination of ... [6] Suhren VG. Inhibitors and residues of veterinary drugs in milk legal ... [7] Tikofsky LL, Barlow JW, Santisteban C, Schukken YH. A comparison of ... [8] Erskine RJ CJ, Schaellibaum M, Yancey R, Zecconi A. Bovine ... [9] Mohsenzadeh M, Bahrainipour A. The detection limits of ... [10] Movassagh MH. Identification of antibiotic residues in raw ... [11] Mahmoudi R, Asadpour, R., Pajouhialamoti, M. R., Golchin, A., Kiyani, R., \& Mohammadpour,R. . Raw cow milk ... [12] HoseinZadeh H, Hanifi, A., Farzamfard, E., Heidary, M., \&Talebi, F. Comparative study on ... [13] Mokhtari A, Hosseini B, Panahi P. ß-Lactams and Tetracyclines Antibiotic ... [14] Delatour T, Savoy M-C, Tarres A, Bessaire T, Mottier P, Desmarchelier A. Low .... [15] Madougou AM, Douny C, Moula N, Scippo M-L, Delcenserie V, Daube G, et al. Survey on the presence of ... [16] T Thrusfield MV. Veterinary epidemiology. Butterworth Heinemann, Londres; 1986, p. 626. [17] Manifi M, Hesari J, Rafat SA. Monitoring of antibiotic residue in raw ... [18] Noori N, Karim G, Raeesian M, Khaneghahi Abyaneh H, Bahonar A, Akhondzadeh Basti A, et al. Antibiotic residues and ... [19] Movassagh MH, Karami AR. Determination of antibiotic residues in bovine milk in ... [20] Sani AM, Nikpooyan H, Moshiri R. Aflatoxin M1 contamination and ... [21] Ghanavi Z. Determination of penicillin G residue in raw and pasteurized milk ... [22] Saltijeral J, Cordova A, Valente V. Antibiotic residues in raw ... [23] Yamaki M, Berruga MI, Althaus RL, Molina MP, Molina A. Occurrence of antibiotic residues in milk from Manchega ewe ... [24] Khaskheli M, Malik RS, Arain MA, Soomro AH, Arain HH. Detection of ... [25] Gidini S, Zanardi E, \&hizzolini R. Prevalence of molecules of $\beta$-lactam antibiotics in bovine milk in ... [26] Rassouli A, Abdolmaleki Z, Bokaee S. A cross sectional study on oxytetracycline and tetracycline ... [27] Fallah Rad AH, Mohsenzadeh M, Asadpour HR. Determination of gentamycin ... [28] Du B, Wen F, Zhang Y, Zheng N, Li S, Li F, et al. Presence of tetracyclines, quinolones, lincomycin, and ... [29] Moghaddam AD, Tayebi L, Falahatpisheh H, Mahmoudian M, Kowsari N, Akbarein H, et al. Evaluation of the ... [30] Faghihi MS. Antibiotics usage in animal farms in Iran and their untoward effects in ... [31] http:// www.fao.org/fao-who-codexalimentarius ... 


\section{Introduction}

Milk and dairy products are known as one of the stuffs and nutrients. Antibiotics such as tetracyclines, beta-lactams (penicillins and cephalosporins), aminoglycosides, sulfonamides, fluoroquinolones, and so on are widely used in mastitis treatment in animals ${ }^{[1]}$. Antibiotics such as antiparasitic, tranquilizing, anti-inflammatory, and growth-promoting agents are broadly used to prevent or treat a great number of diseases and increase feed efficiency ${ }^{[2]}$. When consumption of dairy products is considered as a risk factor for infectious diseases, especially mastitis, antibiotic consumption is certainly fundamental and necessary. Therefore, antibiotic residues could be accumulated in animal-based foods (milk, muscle and liver tissues) ${ }^{[3]}$. Concern about antibiotic residues is related to their undesirable effects on allergic reactions, resistance of bacteria, troublesome of the balance of gut microflora, malformation risks, mutagenesis, and carcinogenesis ${ }^{[4}$, 5]. Also, in industrial level, the presence of antibiotic residues in milk could inhibit starter cultures used to produce cultured milk products such as yogurt and cheeses [6-10]. The presence of antibiotic residues is frequently attributed to the lack of awareness or ignorance of the time interval between antibiotic use and milking and slaughtering of animals or fraud. By processing milk contaminated with antibiotic residues, contamination is not eliminated and remains in other dairy products. Hence, the processes of milk processing, such as drying, evaporating, or ice cream making, are not able to eliminate antibiotic residues from the final products $^{[2]}$.

Different methods are used to measure veterinary antibiotic residues. However, some of them are restricted to rapid, simple, and cost-effective tests (10). Maximum residue limits (MRLs) of antibiotics in animal-based foods have been determined with the aim of protecting consumers' health. European Union law 2002/657/ EC has established rules and guidelines for MRLs of drugs in food. Immunologybased techniques ${ }^{[1]}$ and Copan kit are used to determine drug residue in $15-75 \mathrm{~min}^{[3]}$. Nowadays, microbiological screening tests such as Copan, quantitative methods such as ELISA, and confirmatory methods such as chromatography are proved ${ }^{[1,11-13]}$. Selection of these methods is influenced by the type of antibiotic, the expected time constraints, and the sensitivity of the method ${ }^{[14]}$.

Objectives: This study was undertaken with the aim of evaluating antibiotic residues in milk samples from Qazvin province, Iran by employing ELISA and Copan techniques to check food safety and quality control parameters.

\section{Materials and Methods}

Sampling of milk: Samples were collected from six districts of industrial livestock centers in Qazvin province, Iran in 2019 during summer and winter seasons. The sampling method used was Random cluster, and the sample size was calculated by Equation $1{ }^{[15,16] .}$

$\mathrm{N}=\mathrm{p}^{*}(1-\mathrm{p}) * \mathrm{Z}^{2} / \mathrm{i}^{2}$

(Equation.1)

Where $\mathrm{N}$ is the sample size; $\mathrm{p}$ is the percentage picking a choice, expressed as decimal; $\mathrm{Z}$ is the $\mathrm{Z}$ value (e.g., 1.96 for $95 \%$ confidence level, confidence interval 5\%); and $\mathrm{i}$ is the confidence interval, expressed as decimal. The samples were transported to the laboratory at $4{ }^{\circ} \mathrm{C}$ and preserved at $-20{ }^{\circ} \mathrm{C}$ for further analysis. All the samples $(n=92)$ were confirmed in the laboratory to be screened in terms of somatic cell count higher than $10^{6} \mathrm{~mL}^{-1}$ and bacterial count higher than $5 \times 10^{5} \mathrm{~mL}^{-1}$. 
Copan milk test: The presence or absence of antibiotic residues (gentamicin, tylosin, chloramphenicol, sulfathiazol, sulfamethazine, sulfadioxine, sulfadimethoxine, sulfadiazin, sulfamethoxazole, tetracycline, and penicillinin) in milk samples is determined by the Copan milk test kits (CHR. Hansen, Denmark). Briefly, milk samples are added to the kit (r-Biopharm, Germany) and incubated at $64 \pm 1^{\circ} \mathrm{C}$ for $3 \mathrm{~h}$. If indicator microorganism (Bacillus Stearothermophilus) that feeds on nutrients and grows and turns the culture medium to yellow in the presence of bromocresol of bacteria, is inhibited through lactose fermentation and acid production, no color change occurs in the culture medium, and medium remains purple ${ }^{[17]}$. The samples showing positive responses to the Copan milk test could be analyzed by competitive ELISA kits. The sensitivity and specificity of the Copan kit to the type and amount of antibiotics in milk are shown in Table 1.

ELISA test: RIDASCREEN (r-biopharm,
Germany) antibiotic kits were used to monitor the gentamicin ELISA kit (R5111), chloramphenicol ELISA kit (R1505), tetracycline ELISA kit (R3503), penicilin ELISA kit (R3103), tylosin ELISA kit (R5151), and sulfonamide ELISA kit (R3004) in detecting residues in milk. These kits are competitive enzyme immunoassay used to analyze antibiotic residues in animal products such as milk, honey, and meat. Each kit contains sufficient materials for 96 measurements (one 96-well microplate). Each test kit contains 12 strips with 8 removable wells each, standard concentrations $(0,0.15,0.45,1.35$, and 4.05 $\mathrm{ng} / \mathrm{mL}$ in aqueous solutions), conjugate (peroxidase-conjugated secondary antibodies), antibiotic antibody, substrate (containing urea peroxide), chromogen (containing tetramethylbenzidine), stop solution (1N sulfuric acid), and buffer (sample and standard dilution buffer). The samples showing positive reactions to

Table 1) The sensitivity of the Copan kit to the type and amount of antibiotics

\begin{tabular}{ccc}
\hline Antibiotic & LOD $^{*}(\mathrm{ng} / \mathrm{ml})$ & MRL EU** $\left.^{* *} \mathrm{ng} / \mathrm{ml}\right)$ \\
\hline Gentamicin & $100-500$ & 100 \\
Tylosin & $50-100$ & 50 \\
Chloramphenicol & $>500$ & 0 \\
Sulfathiazol & $50-100$ & 100 \\
Sulfamethazine & $100-200$ & 100 \\
Sulfadioxine & $100-200$ & 100 \\
Sulfadimethoxine & $50-100$ & 100 \\
Sulfadiazin & $50-100$ & 100 \\
Sulfamethoxazole & $<50$ & 100 \\
Tetracycline & $250-500$ & 100 \\
Penicillin & $1-2$ & 4 \\
\hline
\end{tabular}

*LOD, Limit of detection

**MRL, Maximum residue limit authorized by the European Union. 
the Copan milk test were analyzed by competitive ELISA kits. The RIDASCREEN competitive enzyme immunoassay (r-biopharm, Germany) and all the tests were performed according to the manufacturer's instructions to determine antibiotic residues in milk. All the samples were defatted $(50 \mathrm{~mL}$ of the samples were centrifuged at $4000 \mathrm{rpm}$ at a temperature of $40{ }^{\circ} \mathrm{C}$ for $10-15 \mathrm{~min}$ ) and then added to each well, followed by the addition of $50 \mu \mathrm{L}$ of antibody solution. The plate was incubated for $1 \mathrm{hr}$ at $25^{\circ} \mathrm{C}$. Then $250 \mu \mathrm{L}$ of washing buffer was added to each well for washing, washing was repeated three times, and then $100 \mu \mathrm{L}$ of enzyme conjugate was added to each well. The plate was incubation at room temperature for $15 \mathrm{~min}$. Then $50 \mu \mathrm{L}$ of substrate and $50 \mu \mathrm{L}$ of chromogen were added to each well, and the plate was incubated in the dark at room temperature for 15 min. Finally, $100 \mu \mathrm{L}$ of stop solution was added to stop the reaction, and absorbance was recorded at $450 \mathrm{~nm}$ within $30 \mathrm{~min}$. The results were calculated by obtaining the OD values and calculating the percentage of absorbance as follows: \% absorbance $=$ Absorbance standard per sample/Absorbance zero standard $\times 100$. Finally, a calibration curve was plotted between the standard concentration and OD. The limit of detection of the ELISA test is Table 2) Limit of detection (LOD) for ELISA test

\begin{tabular}{cc}
\hline Antibiotic & LOD $(\mathrm{ng} / \mathrm{ml})$ \\
\hline Gentamicin & 2 \\
Tylosin & 2.5 \\
Chloramphenicol & 0.02 \\
Sulfamethazine & 8 \\
Tetracycline & 0.4 \\
Penicillin & 0.08 \\
Flumequine & 13 \\
\hline
\end{tabular}

shown in Table 2.

Data analysis: All the tests were performed in triplicate, and statistical analysis was conducted using analysis of variance (ANOVA) and Chi-square test with SPSS software Ver. 17.0 (SPSS Inc., Chicago, IL, USA). The considered significant level was $p<.05$. The intercept of the standards calibration curve was used to calculate the limit of detection (LOD) around the detection limit. Then the standard deviation (SD) of the response (s) and slope $(\mathrm{S})$ was determined according to the calibration curve. The LOD was considered as $\mathrm{LOD}=(3.3 \times \sigma) / \mathrm{S}$.

\section{Finding}

Based on the obtained results, 45 samples (48.91\%) had antibiotic residues (Table 3). In general, milk samples collected in summer were significantly more contaminated with antibiotic residues (30.43\%) than those collected in winter $(18.47 \%)(p<.05)$. Also, antibiotic residues in the samples collected in both warm and cold seasons were compared and evaluated, and the results are shown in Figure 1. The highest mean concentration was related to sulfonamide $(13.72 \pm 1.21 \mathrm{ng} / \mathrm{mL})$, followed by gentamicin $(13.24 \pm 2.81 \mathrm{ng} / \mathrm{mL})$ and tylosin $(13.15 \pm 1.37$ $\mathrm{ng} / \mathrm{mL}$ ) residues in positive samples, and the lowest mean value was related to penicillin residues $(0.007 \pm 0.002 \mathrm{ng} / \mathrm{mL})$. Most of the contaminated samples contained tetracycline (33.69\%) and chloramphenicol with the lowest rate (21.73\%). The maximum amount of gentamicin in the summer and winter samples was 16.41 and $13.52 \mathrm{ng} / \mathrm{mL}$, respectively.

\section{Discussion}

The results of the present study showed that the samples contamination level was significantly higher in warm seasons compared to cold seasons, and that the highest rate of antibiotic contamination in warm and cold seasons 


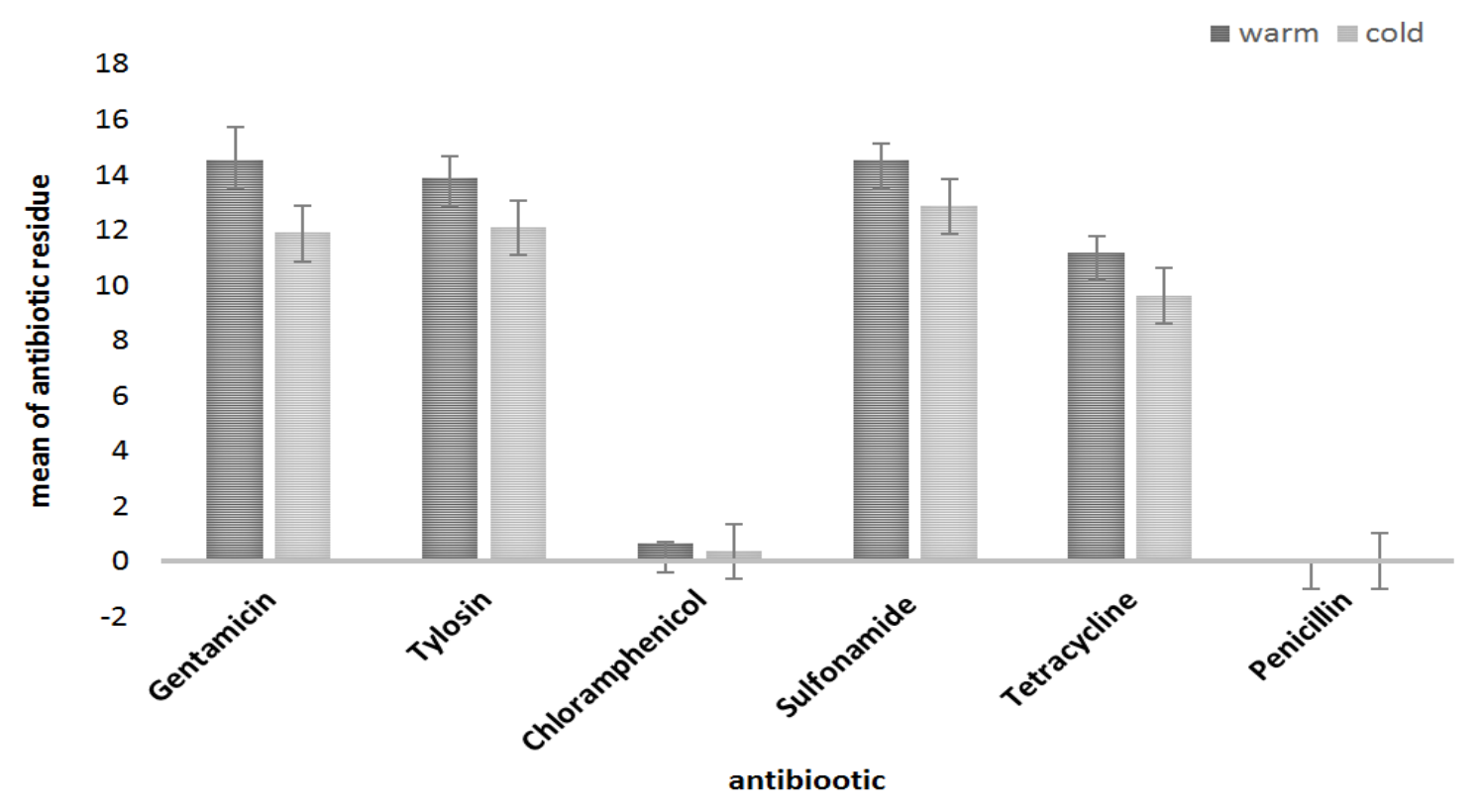

Figure 1) The comparison of antibiotic residues each them in hot and cold seasons

Table 3) Mean values of antibiotic residues in raw milk samples by ELISA

\begin{tabular}{cccccccccc}
\hline Antibiotic & $\begin{array}{c}\text { Positive } \\
\text { samples } \\
\text { (n) }\end{array}$ & $\begin{array}{c}\text { Pamples } \\
\text { (\%) }\end{array}$ & $\begin{array}{c}\text { Mean } \pm \text { SD } \\
\text { (ng/ml) }\end{array}$ & $\begin{array}{c}\text { MRL } \\
\text { Codex } \\
\text { (ng/ml) }\end{array}$ & $\begin{array}{c}\text { n> } \\
\text { MRL } \\
\text { Codex }\end{array}$ & $\begin{array}{c}\text { \%n> } \\
\text { MRL } \\
\text { Codex }\end{array}$ & $\begin{array}{c}\text { MRL } \\
\text { EU } \\
(\mathbf{n g} / \mathbf{m l})\end{array}$ & $\begin{array}{c}\text { MRL } \\
\text { EU }\end{array}$ & $\begin{array}{c}\text { Mn }> \\
\text { MRL }\end{array}$ \\
\hline $\mathrm{G}$ & 29 & 31.52 & $13.24 \pm 2.81$ & 200 & 0 & 0 & 100 & 0 & 0 \\
$\mathrm{~T}$ & 25 & 27.17 & $13.15 \pm 1.37$ & 100 & 0 & 0 & 50 & 0 & 0 \\
$\mathrm{C}$ & 20 & 21.73 & $0.48 \pm 0.02$ & 0 & 20 & 100 & 0 & 20 & 100 \\
$\mathrm{~S}$ & 30 & 32.60 & $13.72 \pm 1.21$ & 25 & 10 & 33.33 & 100 & 0 & 0 \\
$\mathrm{Te}$ & 31 & 33.69 & $10.31 \pm 0.87$ & 100 & 0 & 0 & 100 & 0 & 0 \\
$\mathrm{P}$ & 22 & 23.91 & $0.007 \pm 0.0002$ & 4 & 0 & 0 & 4 & 0 & 0 \\
\hline
\end{tabular}

$\mathrm{G}=$ Gentamicin, $\mathrm{T}=$ Tylosin, $\mathrm{C}=$ Chloramphenicol, $\mathrm{S}=$ Sulfonamides, $\mathrm{Te}=$ Tetracyclin and $\mathrm{P}=$ Penicilin

was related to gentamicin and sulfonamide, respectively, and the lowest contamination rate in warm and cold seasons was related to penicillin. The high level of contamination in milk samples collected in warm season could be due to the higher prevalence of diseases such as mastitis in this season. Therefore, the use of antibiotics and lack of adherence to the antibiotic treatment course could cause antibiotic residues in milk samples to be higher in warm seasons than in cold seasons.
However, according to the hypothesis that in Iran penicillin is used more than other drugs in animal diseases, the results are contradictory. It may be due to the manufacturers' awareness of recent overuse and over-attention to this antibiotic, thereby shifting attentions to more use of other antibiotics. In all the positive samples, chloramphenicol and sulfonamide residues were above the Codex and EC MRLs ( 0 and $25 \mathrm{ng} / \mathrm{mL}$, respectively), but the levels of penicillin, gentamicin, tylosin, and 
tetracycline residues were lower (Table 2). In total, the present study showed that 45 samples (48.91\%) had antibiotic residues, the results are in line with another research by Noori et al. (2013), showing contamination rate of raw milk as $52.5 \%{ }^{[18]}$. Mahmoudi et al., (2013) showed that contamination rate of raw milk was 57.50\% [11]. Movasagh (2012) examining raw milk samples in Eilikhchi (southwest of Tabriz, Iran) using the Copan milk test, showed that $10 \%$ of the samples had antibiotic residues, whereas in another study on 50 raw milk samples in Pars Abad Ardabil, Iran, contamination rate was reported as $14 \%{ }^{[19]}$. In another study, Hoseinzadeh et al. (2012) examined 114 raw milk samples in Giulan, Iran. Their study indicated that $20.17 \%$ of the samples had antibiotic residues, and higher antibiotic residues in winter were attributed to an increase in mastitis in cold seasons and high absorption of antibiotics in animals ${ }^{[12]}$. Mohsenzadeh \& Bahreinipour (2008) studied 300 raw and pasteurized milk samples in Mashhad, Iran. The results showed that contamination was present in 15.3 and $22.2 \%$ of raw and pasteurized milk samples, respectively ${ }^{[9]}$. Manafi et al. (2011) used the Delvo test to examine raw and pasteurized milk sample collected from East Azerbaijan, Iran. They concluded that 26,16 , and $30 \%$ of the milk samples collected from industrialized factory farms, milk collection centers, and pasteurized milk contained antibiotic residues, respectively ${ }^{[17]}$. Similar to the relatively high contamination rate of milk samples collected from the study area, the results of other studies carried out on raw milk samples collected from Shiraz, Sari, Tabriz, and Kazerun cities in Iran, also indicated the presence of antibiotic residues, especially $\beta$-lactams (32.9\%), in milk samples ${ }^{[13]}$. Moreover, in a study carried out in Khorasan province, 196 milk samples were examined using the Copan milk test. The antibiotic residues were present in $40.8 \%$ of the samples ${ }^{[20]}$. Ghanavi (2003) used different methods (like Delvo, Copan, $\beta$-Star, and Cylinder Plate) to study milk samples collected from all over the country. The results showed that contamination rate of raw and pasteurized milk samples was 27 and 5\%, respectively, and that the highest level of contamination was related to $\beta$-lactam antibiotics ${ }^{[21]}$. Also, in another study conducted by Saltijeral et al. (2004) in Mexico, the antibiotic residue in milk was declared to be $77 \%$, which is higher than the values reported in Iran ${ }^{[22]}$. In Spain, Yamaki (2004) studied the presence of $\beta$-lactam residues in milk and reported a contamination level of $1.7 \%$, which is lower than the values reported in Iran ${ }^{[23]}$. On the contrary, Khaskheli and Gidini (2002) in Italy examined the presence of $\beta$-lactam antibiotic residues in milk and reported contamination levels of 36.5 and 49\%, respectively [24, 25]. Furthermore, another study showed that 7.8\% of pasteurized milk samples collected from Tehran were contaminated with tetracycline and oxytetracycline residues ${ }^{[26]}$. Researchers also showed that $7.11 \%$ of raw and pasteurized milk samples contained gentamicin residues [27]. Also, Du et al. (2019b) reported the rates of tetracyclines, quinolones, lincomycin, and streptomycin residues as $4.7,3.3,2.7$, and $15.5 \%$ in UHT milk samples $(\mathrm{n}=148)$ and 16.0 , 4.0,2.0, and $14.0 \%$ in pasteurized milk samples in China, respectively ${ }^{[28]}$. In the present study, in comparison with other antibiotics, the highest contamination rate $(33.69 \%)$ was related to tetracycline with an average of $10.31 \pm 9.87$ $\mathrm{ng} / \mathrm{mL}$. Most studies carried out in Iran have attributed the failure to avoid milking animals after antibiotic consumption as the main reason for the presence of antibiotic residues in milk. However, in developed countries, antibiotic residues in milk are observed following an overdose of medication. Dabbagh Moghaddam et al. (2014) used HPLC method to examine pasteurized milk distributed in Iran and reported that $26.3 \%$ of the positive samples $(8.93 \%$ of the whole samples) were 


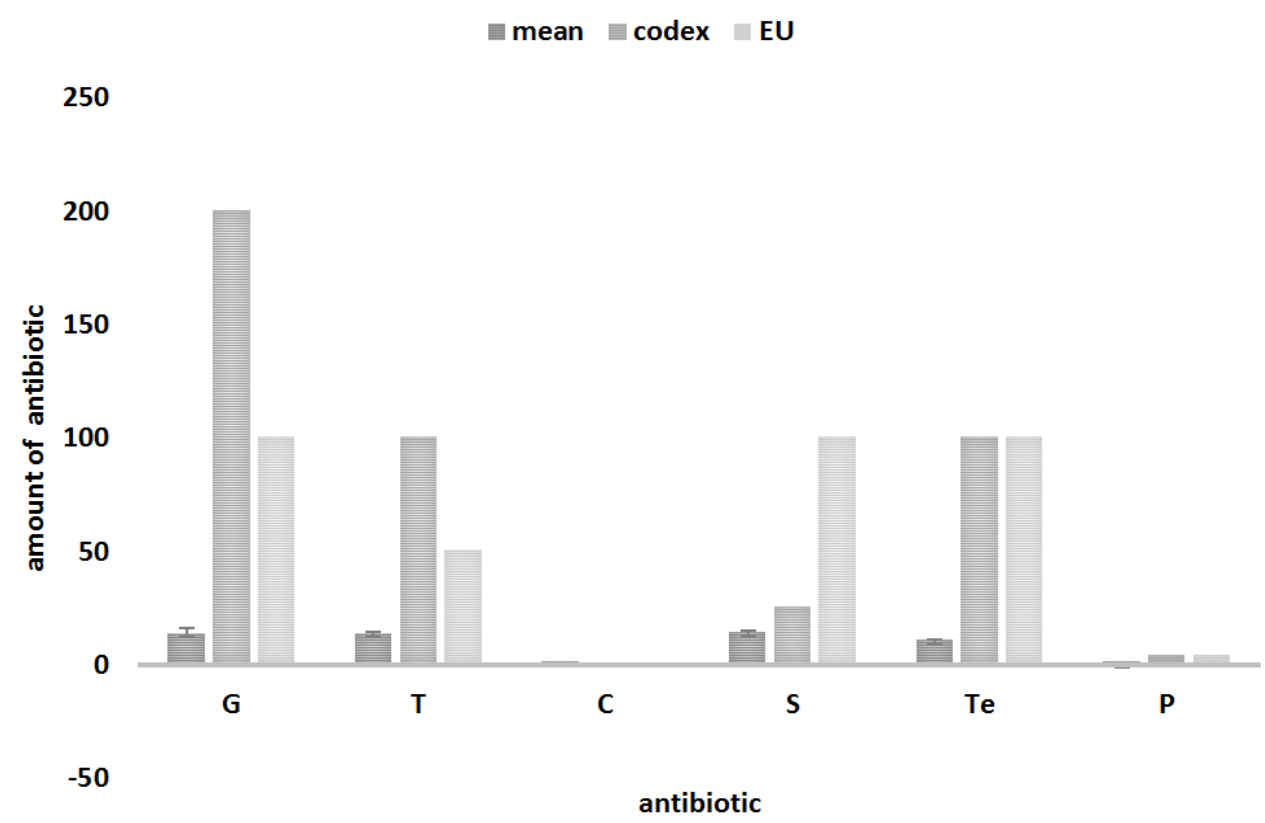

Figure 2) The comparison of antibiotics with the standard of the Codex and the EU ( $G=$ Gentamicin, $T=$ Tylosin, $\mathrm{C}=$ Chloramphenicol, $\mathrm{S}=$ Sulfonamides, $\mathrm{Te}=$ Tetracyclin and $\mathrm{P}=\mathrm{Penicilin}$ )

contaminated with tetracycline MRLs, and other samples contained other types of antibiotics ${ }^{[29]}$. In a study carried out on 220 dairy cattle breeding farms in Tehran and Qom provinces ofIran, Faghihietal.(2010)attributed the high consumption of antibiotics to the high density of livestock in the farms, poor sanitary conditions, and poor management of the farms, which shows the effect of farm management on community health ${ }^{[30]}$. Moreover, in recent years, efforts have also been made to improve the efficiency and accuracy of ELISA; for example, a multiplex finding technology was tested for simultaneous quantification of the four antibiotics quinolones, tetracycline, lincomycin, and streptomycin in milk ${ }^{[2]}$. In order to provide more protection to consumers in European countries, regular measures have been taken regarding the amount of antibiotics used in animal-origin food products, especially milk. For example, the Codex MRLs were reported for gentamicin (200 ng/mL), tetracycline $(100 \mathrm{ng} / \mathrm{mL})$, sulfonamide $(25 \mathrm{ng} / \mathrm{mL})$, tylosin $(100 \mathrm{ng} / \mathrm{mL})$, and penicillin (4 ng/mL) ${ }^{[31]}$. A comparison of antibiotic residues in raw milk samples with existing standards (Codex and EC) is presented in Figure 2. Among the antibiotics examined in the present study, chloramphenicol contamination in all the positive samples was above the Codex and EC MRL ( $0 \mathrm{ng} / \mathrm{mL}$ ); also, the sulfonamide contamination was above the Codex MRL (25 ng/ml) in $33.33 \%$ of positive samples, but the level of penicillin, gentamicin, tylosin, and tetracycline residues was lower (Table 2). The present study results are consistent with the results of the study by $\mathrm{Du}$ et al. (2019b) in China, reporting a detection rate of $1.6-2.8 \%$ with a maximum value of $47.7 \mu \mathrm{g} / \mathrm{kg}$ for tetracycline and a detection rate of 5.8-19.2\% with a maximum detection value of $20.24 \mu \mathrm{g} / \mathrm{kg}$ for sulfonamides in milk samples ${ }^{[28]}$. There is no evidence for penicillin, indicating how much of the drug in milk could be harmful to humans, but the World Health Organization (WHO) and WHO Joint Committee on Food and Agriculture recommend that penicillin residue should not be detectable in human food.

\section{Conclusion}

The present study indicated the contamination of milk samples with antibiotic residues. Since the residues of these compounds have 
adverse effects on the health of people in the community, especially vulnerable groups like children, pregnant women, and elderly patients, there should be a comprehensive action plan to prevent antibiotics abuse in livestock. There are probably several types of antibiotics in milk, even with concentrations below the permitted limit; therefore, their presence could be harmful or beneficial. It is recommended that responsible organizations, especially veterinary organization, have regular supervision on milk contamination in order to reduce sanitary threats to consumers' health. Furthermore, it is necessary that qualified organizations and individuals provide livestock and animal husbandry workers with necessary trainings. Finally, it is crucial to find out rapid and sensitive diagnostic techniques with the shortest detection time and the highest sensitivity to contamination.

Aknowledgements: Authors are thankful from Tehran University of Medical Sciences for the support.

Ethical Permissions: Not applicable. Conflicts of Interests: The authors declared no conflict of interests.

Authors' Contribution: Conceptualization: ZNN; Data curation and formal analysis: ZNN ; Investigation: ZNN; Methodology and project administration: GRJK, EMA; Supervision: GRJK; Validation: EMA; Writing of original draft: MA; Writing, reviewing, and editing: EMA, MA.

Funding: There was no funding.

Consent to participate: Not applicable.

\section{References}

1. Gustavsson E, Degelaen J, Bjurling $\mathrm{P}$, Sternesjo A. Determination of betalactams in milk using a surface plasmon resonance-based biosensor. J Agric Food Chem. 2004; 52(10):2791-6.

2. Du B, Wen F, Guo X, Zheng N, Zhang Y, Li S, et al. Evaluation of an ELISA-based visualization microarray chip technique for the detection of veterinary antibiotics in milk. Food Control. 2019; 106:106713.

3. Wang H, Ren L, Yu X, Hu J, Chen Y, He G, et al. Antibiotic residues in meat, milk and aquatic products in Shanghai and human exposure assessment. Food Control. 2017; 80:217-25.

4. Ronquillo MG, Hernandez JC. Antibiotic and synthetic growth promoters in animal diets: Review of impact and analytical methods. Food Control. 2017; 72:255-67.

5. Tölgyesi Á, Barta E, Sohn M, Sharma VK. Determination of antimicrobial residues in honey by liquid chromatography tandem mass spectrometry. Food Anal Methods. 2018;11(8):2043-55.

6. Suhren VG. Inhibitors and residues of veterinary drugs in milk legal basis, detection methods and detection systems. Kiel Milchwirtsch Forschungsber. 2002; 54(1):35-71.

7. Tikofsky LL, Barlow JW, Santisteban C, Schukken YH. A comparison of antimicrobial susceptibility patterns for Staphylococcus aureus in organic and conventional dairy herds. Microb Drug Resist. 2003;9(Suppl 1):S39-45.

8. Erskine RJ CJ, Schaellibaum M, Yancey R, Zecconi A. Bovine mastitis pathogens and trends in resistance to antibacterial drugs. NMC Annual Meeting; 2004, pp. 400-14.

9. Mohsenzadeh M, Bahrainipour A. The detection limits of antimicrobial agents in cow's milk by a simple yoghurt culture test. Pak J Biol Sci. 2008; 11(18):2282-5.

10. Movassagh MH. Identification of antibiotic residues in raw cow's milk collected from Ilkhchei region (southeast of Tabriz) in spring of 1388. J Food Technol Nutr. 2012; 9(35):89-94.

11. Mahmoudi R, Asadpour, R., Pajouhialamoti, M. R., Golchin, A., Kiyani, R., \& Mohammadpour,R. . Raw cow milk quality: Relationship between antibiotic residue and Somatic cellcount. International Food 
Research J 2013; 20(6):3347-50.

12. HoseinZadeh H, Hanifi, A., Farzamfard, E., Heidary, M., \&Talebi, F. Comparative study on Antibiotic Residue in Ram milk of Gilan Farms during the various seasons. . The 13th Iranian and the 2nd International congress of Microbiology Ardabil, Iran. 2012.

13. Mokhtari A, Hosseini B, Panahi P. $\beta$-Lactams and Tetracyclines Antibiotic Residue Detection in Bulk Tank Milk in Iran. Iranian journal of public health. 2013; 42(4):447-8.

14. Delatour T, Savoy M-C, Tarres A, Bessaire T, Mottier P, Desmarchelier A. Low false response rates in screening a hundred veterinary drug residues in foodstuffs by LC-MS/MS with analyte-specific correction of the matrix effect. Food Control. 2018;94:353-60.

15. Madougou AM, Douny C, Moula N, Scippo M-L, Delcenserie V, Daube G, et al. Survey on the presence of antibiotic residues in raw milk samples from six sites of the dairy pool of Niamey, Niger. Vet World. 2019; 12(12):1970-4.

16. TThrusfield MV.Veterinary epidemiology. Butterworth Heinemann, Londres; 1986, p. 626.

17. Manifi M, Hesari J, Rafat SA. Monitoring of antibiotic residue in raw and pasteurised milk in east Azerbijan of Iran by delvotest method. J Food Res (University of Tabriz). 2011;20/3(2):125-31.

18. Noori N, Karim G, Raeesian M, Khaneghahi Abyaneh H, Bahonar A, Akhondzadeh Basti A, et al. Antibiotic residues and aflatoxin M1 contamination in milkpowder used in Tehran dairy factories, Iran \%J Iranian Journal of Veterinary Medicine. 2013; 7(3):221-6.

19. Movassagh MH, Karami AR. Determination of antibiotic residues in bovine milk in Tabriz, Iran. Global Veterinaria. 2010; 5:195-7.

20. Sani AM, Nikpooyan H, Moshiri R. Aflatoxin M1 contamination and antibiotic residue in milk in Khorasan province, Iran. Food Chem Toxicol. 2010; 48(8-9):2130-2.
21. Ghanavi Z. Determination of penicillin $G$ residue in raw and pasteurized milk from Tehran dairy industries dairy plant. Qazvin Uni Med Sci J. 2003; 22:13-8.

22. Saltijeral J, Cordova A, Valente V. Antibiotic residues in raw milk in Mexico city. Int Soc Anim Hyg- Saint-Malo. 2004;393.

23. Yamaki M, Berruga MI, Althaus RL, Molina MP, Molina A. Occurrence of antibiotic residues in milk from Manchega ewe dairy farms. J Dairy Sci. 2004;87(10):3132-7.

24. Khaskheli M, Malik RS, Arain MA, Soomro $\mathrm{AH}$, Arain HH. Detection of ß-lactam antibiotic residues in market milk. Pak J Nutr. 2008;7(5):682-5.

25. Gidini S, Zanardi E, \&hizzolini R. Prevalence of molecules of $\beta$-lactam antibiotics in bovine milk in lombardia and Emelia Romagna (ITALY), Ann Fac Medic Vet di Parma. 2002;22:245-52.

26. Rassouli A, Abdolmaleki Z, Bokaee S. A cross sectional study on oxytetracycline and tetracycline residues in pasteurized milk supplied in Tehran by an HPLC method. Int J Vet Res. 2010;4(1):1-3.

27. Fallah Rad AH, Mohsenzadeh M, Asadpour HR. Determination of gentamycin residue in raw milk delivered to the milk factory of Mashad. Sci Agric. 2005;20(7):183-9.

28. Du B, Wen F, Zhang Y, Zheng N, Li S, Li F, et al. Presence of tetracyclines, quinolones, lincomycin, and streptomycin in milk. Food Control. 2019;100:171-5.

29. Moghaddam AD, Tayebi L, Falahatpisheh H, Mahmoudian M, Kowsari N, Akbarein $\mathrm{H}$, et al. Evaluation of the tetracycline residues in pasteurized milks distributed in Tehran by HPLC method. Sci Res J Army Univ Med Sci. 2014;11(4):318-23.

30. Faghihi MS. Antibiotics usage in animal farms in Iran and their untoward effects in human health. Front Pharmacol. 2010.

31. http: / / w w w.fao org / fao-whocodexalimentarius/codex-texts/dbs/ vetdrugs /en / 